\title{
C3435T polymorphism of the MDR1 gene is not associated with blood levels of hypothalamus- pituitary-adrenal axis hormones in healthy male subjects
}

A. Suzuki ${ }^{1}$, Y. Matsumoto ${ }^{1}$, T. Shirata ${ }^{1}$, K. Goto ${ }^{2}$, M. Enokido ${ }^{1}$ and K. Otani ${ }^{1}$

${ }^{1}$ Department of Psychiatry,

Yamagata University School of Medicine, Yamagata, Japan

${ }^{2}$ Department of Anatomy and Cell Biology,

Yamagata University School of Medicine, Yamagata, Japan

Corresponding author: A. Suzuki

E-mail: suzukiakihito@hotmail.com

Genet. Mol. Res. 16 (1): gmr16019447

Received October 18, 2016

Accepted December 5, 2016

Published March 8, 2017

DOI http://dx.doi.org/10.4238/gmr16019447

Copyright $(2017$ The Authors. This is an open-access article distributed under the terms of the Creative Commons Attribution ShareAlike (CC BY-SA) 4.0 License.

\begin{abstract}
In vitro studies have shown that multidrug resistance protein 1 (MDR1) has an affinity for cortisol; however, in vivo association studies on the relationship between MDRl gene polymorphisms and blood cortisol levels have produced inconsistent results. Therefore, we examined the effects of the C3435T polymorphism of the MDRI gene on blood levels of hypothalamus-pituitary-adrenal (HPA) axis hormones such as cortisol and adrenocorticotropic hormone (ACTH) in healthy subjects. The subjects comprised 30 healthy Japanese males. Ten subjects were recruited for each of the C3435T MDR1 genotypes: $\mathrm{C} / \mathrm{C}$, $\mathrm{C} / \mathrm{T}$, and $\mathrm{T} / \mathrm{T}$. Blood samples were taken at $6: 00 \mathrm{pm}$ on two occasions with an interval of 2 weeks. Blood levels of cortisol and ACTH were determined by an electrochemiluminescence immunoassay. There were no significant differences in the blood levels of the HPA axis hormones among the MDRl genotypes. The present study suggests that the
\end{abstract}


C3435T MDR1 polymorphism does not affect blood levels of HPA axis hormones in healthy Japanese males.

Key words: $M D R 1$; Polymorphism; HPA axis hormones

\section{INTRODUCTION}

P-glycoprotein 1, or multidrug resistance protein 1 (MDR1), belongs to the adenosine triphosphate (ATP)-binding cassette family of transporters (Fromm, 2004). It is expressed in various tissues such as the intestines, liver, kidney, placenta, and brain, and its physiological role is to prevent the entry and serve as an active eliminator of xenobiotics and cellular metabolites (Fromm, 2004). The human MDR1 gene has the chromosomal locus 7p21, and has a single nucleotide polymorphism in exon 26 at position 3435 (C3435T, rs1045642) (Hoffmeyer et al., 2000). It has been reported that this polymorphism influences MDR1 expression and activity (Hoffmeyer et al., 2000).

The C3435T MDR1 polymorphism has been associated with several neuropsychiatric disorders, i.e., Alzheimer's disease, Parkinson's disease, and epilepsy (Thuerauf and Fromm, 2006). It has also been associated with major depression (Fujii et al., 2012; Ozbey et al., 2014; Santos et al., 2014). Furthermore, our recent study showed a significant association between the C3435T MDR1 polymorphism and interpersonal sensitivity, a depression-prone personality trait, in healthy subjects (Enokido et al., 2014). Because major depression is associated with dysregulated function of the hypothalamus-pituitary-adrenal (HPA) axis (Binder and Nemeroff, 2010), these associations between the MDR1 polymorphism and depression may be mediated by altered HPA axis hormones.

In vitro studies have shown that MDR1 has an affinity for cortisol as well as other endogenous steroid hormones such as estradiol and progesterone (Uhr et al., 2002; Kim and Benet, 2004; Peng et al., 2016). However, in vivo studies have produced inconsistent results. Lacchini et al. (2014) reported that the C3435T MDR1 polymorphism did not influence plasma levels of cortisol in 83 resistant hypertensive patients treated with anti-hypertensive drugs that may affect MDR1 activity (Wynn et al., 2009). Moreover, Nakamura et al. (2009) examined the effects of the C3435T MDR1 polymorphism on serum levels of cortisol, and showed that the $\mathrm{C}$ allele was associated with higher serum levels of the hormone during the post-menstrual phase in 18 healthy females, although this association was not found during the premenstrual and menstrual phases. Therefore, we examined the effects of the C3435T MDR1 polymorphism on blood levels of HPA axis hormones in healthy males taking no medications, to determine whether the HPA axis hormones are implicated in the link between the MDR1 polymorphism and major depression.

\section{MATERIAL AND METHODS}

Thirty healthy Japanese males were recruited from the staff at Yamagata University Hospital. They had already been genotyped for the C3435T MDR1 polymorphism in our previous study examining the association between this polymorphism and personality traits (Enokido et al., 2014). Ten subjects were recruited for each of the genotypes: $\mathrm{C} / \mathrm{C}, \mathrm{C} / \mathrm{T}$, and $\mathrm{T} / \mathrm{T}$. The mean age $\pm \mathrm{SD}$ (range) was $27.8 \pm 2.0(25-32)$ years. None of the subjects had taken any drugs that are MDR1 substrates for at least two weeks prior to commencement of the

Genetics and Molecular Research 16 (1): gmr16019447 
study. The subjects' characteristics are given in Table 1. The study protocol was approved by the Ethics Committee of Yamagata University School of Medicine, and all subjects provided written informed consent before participation.

Table 1. Effects of the MDR1 genotypes on blood levels of hypothalamus-pituitary-adrenal (HPA) axis hormones.

\begin{tabular}{l|c|c|c|c|c|c}
\hline & Total subjects & \multicolumn{3}{|c|}{ MDR1 genotype } & F & P \\
\cline { 3 - 6 } & & $\mathrm{C} / \mathrm{C}$ & $\mathrm{C} / \mathrm{T}$ & $\mathrm{T} / \mathrm{T}$ & & \\
\hline No. of subjects & 30 & 10 & 10 & $27.4 \pm 1.6$ & 1.754 & \\
\hline Age $($ years & $27.8 \pm 2.0$ & $27.8 \pm 2.5$ & $27.2 \pm 1.5$ & $169.2 \pm 7.2$ & 2.186 & 0.192 \\
\hline Height $(\mathrm{cm})$ & $172.1 \pm 6.3$ & $174.9 \pm 5.9$ & $172.2 \pm 5.0$ & $60.3 \pm 11.2$ & 1.165 & 0.32 \\
\hline Body weight $(\mathrm{kg})$ & $63.7 \pm 8.9$ & $65.0 \pm 8.0$ & $65.9 \pm 6.6$ & $26.9 \pm 8.3$ & 0.129 & 0.879 \\
\hline ACTH $(\mathrm{pg} / \mathrm{mL})$ & $25.4 \pm 11.0$ & $24.6 \pm 16.0$ & $24.6 \pm 7.9$ & $9.6 \pm 3.4$ & 0.420 & 0.661 \\
\hline Cortisol $(\mu \mathrm{g} / \mathrm{dL})$ & $9.9 \pm 3.4$ & $9.2 \pm 2.9$ & $10.4 \pm 2.8$ & & \\
\hline
\end{tabular}

MDR1 $=$ multidrug resistance $1 ; \mathrm{ACTH}=$ adrenocorticotropic hormone. Numbers represent means $\pm \mathrm{SD}$.

Blood samples were taken at $6 \mathrm{pm}$ on two occasions with a 2-week interval. The time of sampling was determined based on the evidence provided by previous studies (Parry et al., 2000; Nakamura et al., 2009), which suggest that cortisol levels peak early in the morning, decline within several hours, then remain relatively stable in the evening. Cortisol levels are influenced by a substantial number of factors such as sleep duration, physical activity, and night-shift work (Kudielka et al., 2006; Mirick et al., 2013). Therefore, the subjects were free to follow their normal daily work routines on both sampling days, and were advised to get enough sleep the day before the samples were taken. They were prohibited from eating, drinking anything, or vigorous physical activity for at least three hours before blood sampling. Serum levels of cortisol and plasma levels of adrenocorticotropic hormone (ACTH) were measured using Roche Diagnostics Elecsys electrochemiluminescence immunoassays for cortisol and ACTH (Roche Diagnostics K.K., Tokyo, Japan), respectively. The means of the hormone levels measured on the two sampling occasions were used for statistical analyses.

Statistical analyses were performed by analysis of variance using SPSS $14.0 \mathrm{~J}$ for Windows (SPSS Japan Inc., Tokyo, Japan). A P-value of less than 0.05 was regarded as significant.

\section{RESULTS}

Contrary to our expectations, there were no significant differences in the blood levels of cortisol $(\mathrm{P}=0.661)$ or ACTH $(\mathrm{P}=0.879)$ among the three MDRl genotypes (Table 1).

\section{DISCUSSION}

In the present study, we found that the C3435T MDR1 polymorphism does not affect blood levels of cortisol or ACTH in healthy Japanese males. The effect size at $\alpha=0.05$ and at power 0.80 in the present sample size was 0.176 (Cohen, 1988). This means that we would only have detected a significant difference among the groups if one group had had a mean score of at least 0.176 times the standard deviation of the other groups. Thus, the present study suggests that the C3435T MDR1 polymorphism does not have a great impact on blood levels of cortisol or ACTH.

Genetics and Molecular Research 16 (1): gmr16019447 
The lack of association between the C3435T MDR1 polymorphism and cortisol levels was not in accordance with a previous study that showed that the $\mathrm{C}$ allele of this polymorphism was associated with higher cortisol levels in 18 healthy women during the postmenstrual phase (Nakamura et al., 2009). In vitro studies have shown that MDR1 expression is lower in females than in males, suggesting sex specificity of MDR1 expression, possibly due to the effects of estradiol and progesterone (Kim and Benet, 2004). Thus, the inconsistency between the two studies may be ascribed to the gender difference of the subjects. Incidentally, we found the same sex specificity in our previous study, i.e., we found a significant association between the C3435T MDR1 polymorphism and the interpersonal sensitivity personality trait in females but not in males (Enokido et al., 2014). Moreover, it has been suggested that the test-retest reliability of HPA axis assessment varies widely among procedures, and other assessment methods such as diurnal salivary cortisol curve and cortisol awakening response may be more reliable for testing HPA axis function than single-point measurements (Golden et al., 2011). Thus, it is possible that the effects of the MDR1 polymorphism on HPA hormones were not reliably detected by the single-point measurement method used in the present study. Further studies using the other assessment methods mentioned above are warranted. In conclusion, the present study suggests that the C3435T MDR1 polymorphism does not affect blood levels of HPA axis hormones in healthy Japanese males.

\section{Conflicts of interest}

The authors declare no conflict of interest.

\section{ACKNOWLEDGMENTS}

Research supported by funding from the Ministry of Education, Culture, Sports, Science, and Technology of Japan.

\section{REFERENCES}

Binder EB and Nemeroff CB (2010). The CRF system, stress, depression and anxiety-insights from human genetic studies. Mol. Psychiatry 15: 574-588.- http://dx.doi.org/10.1038/mp.2009.141

Cohen J (1988). Statistical Power Analysis for the Behavioral Sciences. Lawrence Erlbaum Associates, Publishers, Hillsdale, New Jersey, USA.

Enokido M, Suzuki A, Sadahiro R, Matsumoto Y, et al. (2014). Implication of P-glycoprotein in formation of depressionprone personality: association study between the C3435T MDR1 gene polymorphism and interpersonal sensitivity. Neuropsychobiology 69: 89-94.- http://dx.doi.org/10.1159/000358063

Fromm MF (2004). Importance of P-glycoprotein at blood-tissue barriers. Trends Pharmacol. Sci. 25: 423-429.- http:// dx.doi.org/10.1016/j.tips.2004.06.002

Fujii T, Ota M, Hori H, Sasayama D, et al. (2012). Association between the functional polymorphism (C3435T) of the gene encoding P-glycoprotein (ABCB1) and major depressive disorder in the Japanese population. J. Psychiatr. Res. 46: 555-559.- http://dx.doi.org/10.1016/j.jpsychires.2012.01.012

Golden SH, Wand GS, Malhotra S, Kamel I, et al. (2011). Reliability of hypothalamic-pituitary-adrenal axis assessment methods for use in population-based studies. Eur. J. Epidemiol. 26: 511-525.- http://dx.doi.org/10.1007/s10654-0119585-2

Hoffmeyer S, Burk O, von Richter O, Arnold HP, et al. (2000). Functional polymorphisms of the human multidrugresistance gene: multiple sequence variations and correlation of one allele with P-glycoprotein expression and activity in vivo. Proc. Natl. Acad. Sci. USA 97: 3473-3478.= http://dx.doi.org/10.1073/pnas.97.7.3473

Kim WY and Benet LZ (2004). P-glycoprotein (P-gp/MDR1)-mediated efflux of sex-steroid hormones and modulation

Genetics and Molecular Research 16 (1): gmr16019447 
of P-gp expression in vitro. Pharm. Res. 21: 1284-1293.- http://dx.doi.org/10.1023/B:PHAM.0000033017.52484.81 Kudielka BM, Federenko IS, Hellhammer DH and Wüst S (2006). Morningness and eveningness: the free cortisol rise after awakening in "early birds" and "night owls". Biol. Psychol. 72: 141-146.= http://dx.doi.org/10.1016/j. biopsycho.2005.08.003

Lacchini R, Figueiredo VN, Demacq C, Coeli-Lacchini FB, et al. (2014). MDR-1 C3435T polymorphism may affect blood pressure in resistant hypertensive patients independently of its effects on aldosterone release. J. Renin Angiotensin Aldosterone Syst. 15: 170-176.- http://dx.doi.org/10.1177/1470320312466124

Mirick DK, Bhatti P, Chen C, Nordt F, et al. (2013). Night shift work and levels of 6-sulfatoxymelatonin and cortisol in men. Cancer Epidemiol. Biomarkers Prev. 22: 1079-1087.- http://dx.doi.org/10.1158/1055-9965.EPI-12-1377

Nakamura T, Okamura N, Yagi M, Omatsu H, et al. (2009). Effects of ABCB1 3435C $>$ T genotype on serum levels of cortisol and aldosterone in women with normal menstrual cycles. Genet. Mol. Res. 8: 397-403.- http://dx.doi. org/10.4238/vol8-2gmr574

Ozbey G, Yucel B, Taycan SE, Kan D, et al. (2014). ABCB1 C3435T polymorphism is associated with susceptibility to major depression, but not with a clinical response to citalopram in a Turkish population. Pharmacol. Rep. 66: 235238.- http://dx.doi.org/10.1016/j.pharep.2013.09.004

Parry BL, Javeed S, Laughlin GA, Hauger R, et al. (2000). Cortisol circadian rhythms during the menstrual cycle and with sleep deprivation in premenstrual dysphoric disorder and normal control subjects. Biol. Psychiatry 48: 920-931.= http://dx.doi.org/10.1016/S0006-3223(00)00876-3

Peng R, Zhang H, Zhang Y and Wei DY (2016). Impacts of ABCB1 (G1199A) polymorphism on resistance, uptake, and efflux to steroid drugs. Xenobiotica 46: 948-952.- http://dx.doi.org/10.3109/00498254.2016.1138249

Santos M, Carvalho S, Lima L, Nogueira A, et al. (2014). Common genetic polymorphisms in the ABCB1 gene are associated with risk of major depressive disorder in male Portuguese individuals. Genet. Test. Mol. Biomarkers 18: 12-19.= http://dx.doi.org/10.1089/gtmb.2013.0197

Thuerauf N and Fromm MF (2006). The role of the transporter P-glycoprotein for disposition and effects of centrally acting drugs and for the pathogenesis of CNS diseases. Eur. Arch. Psychiatry Clin. Neurosci. 256: 281-286.- http:// dx.doi.org/10.1007/s00406-006-0662-6

Uhr M, Holsboer F and Müller MB (2002). Penetration of endogenous steroid hormones corticosterone, cortisol, aldosterone and progesterone into the brain is enhanced in mice deficient for both mdrla and mdrlb P-glycoproteins. J. Neuroendocrinol. 14: 753-759.: http://dx.doi.org/10.1046/j.1365-2826.2002.00836.x

Wynn GH, Oesterheld JR, Cozza KL and Armstrong SC (2009). Clinical manual of drug interaction principles for medical practice. American Psychiatric Publishing, Inc., Arlington. 